\title{
STORE ATMOSPHERE DALAM MENINGKATKAN KEPUTUSAN PEMBELIAN PADA RESTORAN KAPAL JODOH BATU MARMAR PAMEKASAN
}

\author{
Nuer Riskiyah \\ Institut Agama Islam Al-Khairat Pamekasan \\ esy@alkhairat.ac.id \\ Aang Kunaifi \\ Institut Agama Islam Al-Khairat Pamekasan \\ angkunaifi@alkhairat.ac.id \\ Matnin \\ Institut Agama Islam Al-Khairat Pamekasan \\ Fatih.matnin@gmail.com \\ Qaiyim Asyari \\ Institut Agama Islam Al-Khairat Pamekasan \\ qaiyim90@gmail.com
}

Abstract: The purpose of this study was conducted with the main objective to be achieved, namely to determine the store atmosphere and purchase decisions at the Jodoh Tamberu Alet Ship Restaurant, Batu Marmar District. Atmospheric refreshes to the store's physical characteristics that are used to develop an image and to draw customers, which means that a cafe atmosphere is a physical characteristic used to build an impression and to attract customers. The elements of the atmosphere can be operationalized in the restaurant as objects in this study, namely: Layout, sound, smell, texture, building design. The study will contain data quotations to provide an overview of the presentation of the report. The data may come from manuscripts of interviews with owner and management, field notes, photos, notes or memos directly from the location. Data collection procedures used in this study were interviews, observation and documentation. The analysis used in this research is non-statistical analysis. This study analyzes data from interviews, observations, and documentation. The stages of analysis carried out by researchers in this study are as follows: Reduction, Display, Conclusion drawing. Based on literature review, the results of field research and data analysis, the researcher can conclude that the store atmosphere in the form of layout, sound, smell, texture and building design in a restaurant has an impact in increasing purchasing decisions on matchmaking vessels. This is because consumers tend to enjoy the restaurant atmosphere other than just enjoying food.

Keywords: Store atmosphere, purchase decision, café, restaurant.

Abstrak: Tujuan penelitian ini dilakukan dengan tujuan utama yang hendak dicapai yaitu untuk mengetahui store atmosphere dan keputusan pembelian pada Restoran Kapal Jodoh Tamberu 
Alet Kecamatan Batu Marmar. Atmosphere refers to the store's physical characteristics that are used to develop an image and to draw customers, yang berarti suasana cafe merupakan karakteristik fisik yang digunakan untuk membangun kesan dan untuk menarik pelanggan. Elemen-elemen atmosphere dapat dioperasionalkan pada restoran sebagai obyek dalam penelitian ini yaitu: Layout, suara, bau, tekstur, desain bangunan. Penelitian akan berisi kutipan-kutipan data untuk memberi gambaran penyajian laporan tersebut. Data tersebut kemungkinan berasal dari naskah wawancara terhadap owner dan manajemen, catatan lapangan, foto, catatan atau memo langsung dari lokasi. Prosedur pengumpulan data yang digunakan dalam penelitian ini adalah wawancara, observasi dan dokumentasi. Analisis yang digunakan dalam penelitian ini adalah analisis non statistik. Penelitian ini menganalisis data dari hasil wawancara, observasi, dan dok umentasi. Adapun tahap-tahap analisis yang dilakukan oleh peneliti dalam penelitian ini sebagai berikut: Reduksi, Display, Conclusion drawing. Berdasarkan kajian pustaka, hasil penelitian di lapangan dan analisis data, maka peneliti dapat menyimpulkan bahwa Store atmosphere yang berupa lay out, suara, bau, tekstur dan desain bangunan pada sebuah restoran sangat memberi dampak dalam meningkatkan keputusan pembelian pada kapal jodoh. Hal ini diakibatkan konsumen cenderung menikmati suasana restoran selain hanya menikmati makanan.

Kata Kunci: Store atmosphere, keputusan pembelian, café, restoran. 

Store Atmosphere ...

\section{A. Pendahuluan}

Indonesia merupakan salah satu negara yang telah memasuki era persaingan global, tidak ada batasan dalam setiap individu untuk mengembangkan bisnis baik dalam lingkup kecil, menengah maupun besar. Hal tersebut mengakibatkan para pelaku bisnis akan berlomba-lomba untuk memberikan layanan sebaik mungkin sehingga dapat memberikan kepuasan kepada konsumen/pengunjung.

Kondisi persaingan dalam ekonomi menuntut setiap pelaku bisnis untuk mampu bersaing dan bertahan melawan pesaing lainnya. Banyaknya pelaku bisnis yang berlomba untuk mendapatkan konsumen menjadikan kondisi berlangsung semakin ketat. Persaingan yang sangat ketat menuntut para pelaku bisnis untuk dapat menentukan strategi yang tepat dalam berkompetisi, yaitu menyediakan kebutuhan konsumen yang selalu bervariasi.

Kebutuhan konsumen yang bervariasi tersebut, kemudian memunculkan kreativitas dalam dunia pemasaran, guna menarik konsumen agar melakukan pembelian, salah satunya dapat dilakukan dengan kreativitas penciptaan suasana (Atmosphere) yang menyenangkan dan menarik di dalam toko atau restoran. Dewasa ini ada kecenderungan berubahnya motif seseorang untuk berbelanja, di mana kegiatan berbelanja tidak hanya sebagai kegiatan fungsional untuk membeli barang kebutuhan saja, tetapi juga kegiatan untuk rekreasi, hiburan atau hanya untuk pelepas stres.

Artinya, saat konsumen masuk ke sebuah tempat yaitu toko, café maupun restoran, mereka tidak hanya memberikan penilaian terhadap produk yang ditawarkan tetapi juga akan memberikan penilaian terhadap kreativitas penciptaan suasana pada tempat tersebut.

Menghadirkan Store Atmosphere. desain lingkungan melalui komunikasi visual, pencahayaan, warna, musik, dan wangi-wangian akan merancang respon emosional dan persepsi pelanggan untuk mempengaruhi pelanggan dalam membeli barang. Pemahaman umumnya store atmosphere adalah penataan lingkungan toko atau restoran meliputi desain interior dan eksterior yang dapat memberi kesan pada konsumen. Selanjutnya konsumen 
bisa merasakan kenyamanan yang diinginkan dan akan mendorong konsumen untuk melakukan keputusan pembelian.

Layout (tata letak) merupakan pengaturan secara fisik dan penempatan barang dagangan, perlengkapan tetap. Sedangkan suara merupakan keseluruhan musik yang dihadirkan. Banyak keputusan pembelian yang didasarkan pada emosi, dan bau memiliki dampak besar pada emosi konsumen. Bau lebih dari indera lainnya sebagai penentu perasaan gembira, kelaparan, enggan untuk mengkonsumsi, dan nostalgia.

Tekstur adalah unsur rupa yang menunjukkan rasa permukaan bahan, yang sengaja dibuat dan dihadirkan dalam susunan untuk mencapai bentuk rupa, dengan pengolahan tekstur atau bahan yang baik, maka tata ruang luarnya akan menghasilkan kesan dan kualitas ruang yang lebih menarik dan mampu mempengaruhi pengunjung berkunjung dan melakukan pembelian. sedangkan desain memiliki peran yang sangat penting untuk menimbulkan kesan nyaman, baik untuk penyewa atau pengunjung dalam beraktivitas.

Store atmosphere sebagai strategi pemasaran dirancang untuk memberikan kenyamanan dan keamanan agar emosi konsumen/pengunjung yang sebelumnya hanya berniat berkunjung, pada kelanjutannya menyatakan kesediaannya untuk berbelanja di toko yang bersangkutan. Oleh karena itu, store Atmosphere menjadi salah satu faktor melakukan pembelian di toko, café atau restoran. jika semakin nyaman suatu toko semakin banyak konsumen/pengunjung tertarik berbelanja ataupun berkunjung pada toko tersebut. Desain toko yang baik dapat pula menarik keinginan konsumen/pengunjung untuk mengetahui lebih dalam mengenai segala sesuatu yang ditawarkan oleh toko tersebut. Hal tersebut, dapat menjadi tolak ukur bagaimana konsumen/pengunjung mengambil keputusan dalam melakukan transaksi.

Keputusan konsumen merupakan tindakan konsumen dalam memutuskan sebuah produk yang dianggap menjadi solusi dari kebutuhan dan keinginan konsumen. Secara garis besar, faktor-faktor yang mempengaruhi keputusan pembelian oleh konsumen akhir 
Store Atmosphere ...

dapat dikelompokkan menjadi empat kategori faktor personal meliputi seperti; usia dan tahap siklus hidup, pekerjaan dan lingkungan ekonomi, gaya hidup, dan kepribadian dan konsep diri. Faktor psikologis meliputi: motivasi, persepsi, pembelajaran, keyakinan dan sikap. Faktor sosial meliputi: teman, keluarga dan komunitas social. Terakhir, faktor kultural meliputi: kebudayaan, sub budaya, dan kelas sosial.

Setiap toko berusaha menciptakan store atmosphere yang baik agar bisa mempengaruhi calon konsumen/pengunjung, termasuk Restoran Kapal Jodoh. Kapal Jodoh merupakan sebuah restoran yang terletak di Tamberu Alet Kecamatan Batu Marmar Kabupaten Pamekasan. Restoran ini mengusung konsep di atas kapal memiliki pemandangan laut lepas. Restoran Kapal Jodoh tidak hanya menawarkan makanan ringan, tetapi juga panorama pantai yang indah dengan pesona sunset (matahari terbenam) pada sore hari dan lampu warna warni yang elegan pada malam hari, sehingga sangat nyaman untuk menyantap makanan ringan atau berdiskusi bersama orang-orang terdekat.

Tempat makan kapal jodoh menjadi lokasi ber-swafoto. Karena bentuk bangunannya yang instagrambale ditambah dengan latar belakang panorama pantai utara Madura yang indah. Berkat keunikannya kapal jodoh menjadi populer dan banyak didatangi para pengunjung khususnya warga Madura. Menurut owner, alasan utama membuat kapal jodoh dikarenakan kondisi ekonomi keluarga yang memprihatinkan, dan keinginan untuk membantu perekonomian warga sekitar dengan menjadikan mereka karyawan disana.

\section{B. Kajian Pustaka}

Elemen Store Atmosphere

Elemen-elemen atmosphere dapat dioperasionalkan pada restoran sebagai obyek dalam penelitian ini yaitu:

I. Layout

Layout (tata letak) merupakan pengaturan secara fisik dan penempatan barang dagangan, perlengkapan tetap. Bertujuan untuk memberikan gerak pada konsumen, memperlihatkan barang dagangan atau jasa, yang mampu menarik dan memaksimalkan 
penjualan. Sebuah layout dapat bekerja dan mencapai tujuan yang dimaksud apabila pesanpesan yang akan disampaikan dapat dipahami oleh pengunjung.

\section{Suara}

Suara merupakan keseluruhan musik yang dihadirkan, kehadiran musik bagi usaha restoran sangat penting karena dapat memberikan peningkatan kualitas pelayanan dalam menyajikan pengalaman belanja atau menikmati produk yang menyenangkan bagi para pengunjung sehingga mampu mempengaruhi emosi pengunjung untuk melakukan pembelian. Menurut penjelasan tersebut maka dapat disimpulkan bahwa musik adalah bagian penting untuk melengkapi kenyamanan pengunjung.

3. Bau

Keputusan pembelian yang didasarkan pada emosi, dan bau memiliki dampak besar pada emosi konsumen. Bau lebih dari indera lainnya sebagai penentu perasaan gembira, kelaparan, enggan untuk mengkonsumsi, dan nostalgia.

\section{Tekstur}

Tekstur adalah unsur rupa yang menunjukkan rasa permukaan bahan, yang sengaja dibuat dan dihadirkan dalam susunan untuk mencapai bentuk rupa, sebagai usaha untuk memberikan rasa tertentu pada permukaan bidang, pada perwajahan bentuk, pada karya seni rupa secara nyata atau semu. Pengolahan tekstur atau bahan yang baik, maka tata ruang luarnya akan menghasilkan kesan dan kualitas ruang yang lebih menarik dan mampu mempengaruhi pengunjung berkunjung dan melakukan pembelian.

\section{Desain Bangunan}

Desain selalu dikaitkan dengan seni atau keindahan, dimana eksterior adalah cermin awal dari pengunjung ataupun penyewa dalam beraktivitas di sebuah pusat perbelanjaan. Desain memiliki peran yang sangat penting untuk menimbulkan kesan nyaman, baik untuk penyewa atau pengunjung dalam beraktivitas.

Volume. 8/No. 2/Juli 2020 Al-Iqtishod | 57 
Store Atmosphere ...

\section{Metode Penelitian}

Penelitian akan berisi kutipan-kutipan data untuk memberi gambaran penyajian laporan tersebut. Data tersebut kemungkinan berasal dari naskah wawancara terhadap owner dan manajemen, catatan lapangan, foto, catatan atau memo langsung dari lokasi. Prosedur pengumpulan data yang digunakan dalam penelitian ini adalah wawancara, observasi dan dokumentasi. Analisis yang digunakan dalam penelitian ini adalah analisis non statistik. Penelitian ini menganalisis data dari hasil wawancara, observasi, dan dok umentasi. Adapun tahap-tahap analisis yang dilakukan oleh peneliti dalam penelitian ini sebagai berikut: Reduksi, Display, Conclusion drawing.

\section{Hasil dan Pembahasan}

\section{PROFILE STORE ATMOSPHERERESTORAN KAPAL JODOH}

Store atmosphere di Restoran Kapal Jodoh Tamberu Alet Kecamatan Batu Marmar, dapat dilihat dalam tiga hal yaitu:

I. Area parkir luas

Menurut Mischitelli restoran sebaiknya mempunyai tempat parkir sendiri atau menggunakan tempat parkir umum yang luas, nyaman, dan aman baik untuk kendaraan roda dua maupun roda empat. ${ }^{1}$ Area parkir luas merupakan hal penting bagi konsumen. Jika tempat parkir luas, aman dan mempunyai jarak yang dekat dengan restoran akan menciptakan atmosphere yang positif pada restoran tersebut.

Pada kapal jodoh sendiri, area parkir berada pada sisi samping kapal, luas area yang mampu menampung beberapa mobil dan sepeda motor, memberikan kenyamanan tersendiri bagi pengunjung. Selain itu, akses mudah dari jalan raya dikarenakan tempat yang berada tepat di pinggir jalan memudahkan pengunjung ketika akan keluar masuk pada restoran tersebut. Keamanan yang terjaga dikarenakan ada satpam yang merangkap tukang parkirpun lebih membuat pengunjung tenang akan keselamatan kendaraannya.

2. Pencahayaan yang baik

\footnotetext{
${ }^{\text {I }}$ Desy Purwanti Atmaja dan Martinus Febrian Adiwinata, "Layanan Terhadap Keputusan Pembelian di Kopitiam Oey Surabaya”, Jurnal Hospitality dan Manajemen Jasa, Vol I, No 2 (2013), 553.
} 
Pencahayaan (Iluminasi) adalah salah satu elemen perancangan ruang dalam maupun ruang luar yang penting, baik secara arsitektur maupun interior. ${ }^{2}$ Setiap restoran harus memiliki pencahayaan yang cukup untuk mengarahkan atau menarik perhatian konsumen ke daerah tertentu dari restoran tersebut. Konsumen yang berkunjung akan tertarik pada sesuatu yang paling terang yang berada dalam pandangan mereka. Tata cahaya yang baik memiliki kualitas dan warna yang dapat membuat suasana yang ditawarkan terlihat lebih menarik, terlihat berbeda bila dibandingkan dengan keadaan sebenarnya.

3. Kualitas pelayanan yang baik

Kualitas layanan menurut Parasuraman merupakan perbandingan antara layanan yang dirasakan (persepsi) konsumen dengan kualitas layanan yang diharapkan konsumen. ${ }^{3}$ Karyawan yang sopan, ramah,berpenampilan menarik, cepat dan tanggap akan menciptakan citra sebuah restoran dan loyalitas konsumen dalam segi pelayanan.

\section{KEPUTUSAN PEMBELIAN PADA RESTORAN KAPAL JODOH}

Beberapa temuan dalam keputusan pembelian yaitu:

I. Harga makanan dan minuman

Menurut Kotler dan Amstrong harga merupakan sejumlah uang yang ditagihkan atas suatu produk atau jasa, atau jumlah dari nilai yang ditukarkan para pelanggan untuk memperoleh manfaat dari memiliki atau menggunakan suatu produk atau jasa ${ }^{4}$. Maka dari itu ketika berkunjung kesebuah restoran, konsumen akan disuguhkan daftar menu makanan dan minuman. Konsumen bisa memesan makanan atau minuman sesuai dengan keinginan dan harga yang ramah dikantong.

2. Suasana Hati ( Emotional Value)

\footnotetext{
${ }^{2}$ Mila Andria Savitri, " Peran Pencahayaan Buatan salam Pembentukan Suasana dan Citra Ruang Komersial (Studi Kasus pada Interior Beberapa Restoran Tematik di Bandung)", Jurnal Ambience, 3.

${ }^{3}$ Selvy Normasari, Srikandi Kumadji, dan Andriani Kusumawati, " Pengaruh Kualitas Pelayanan Terhadap Kepuasan Pelanggan, Citra Perusahaan Dan Loyalitas Pelanggan (Survei pada Tamu Pelanggan yang Menginap di Hotel Pelangi Malang)", Jurnal Administrasi Bisnis (JAB), Vol 6, No 2 (Desember 2013), 3. ${ }^{4}$ Jefry F.T. Bailia, A.S Soegoto dan S. SR. Loindong, "Pengaruh Kualitas Produk, Harga dan Lokasi terhadap Kepuasan Konsumen pada Warung-warung Makan Lamongan di Kota Manado", Jurnal EMBA, Vol 2, No 3 ( September 2014), I770.
}

Volume. 8/No. 2/Juli 2020 Al-Iqtishod | 59 
Store Atmosphere ...

Emotional Value, Utilitas yang berasal dari perasaan atau afektif atau emosi positif yang ditimbulkan dari mengkonsumsi produk. ${ }^{5}$ sebuah restoran sebenarnya bukan hanya berfungsi sekedar tempat makan dan memuaskan rasa lapar konsumen, tetapi juga harus memenuhi kebutuhan suasana hati untuk rileks, merangsang ide-ide baru, dan juga sebagai tempat mengobrol yang nyaman.

3. Kebersihan lingkungan

Kebersihan lingkungan restoran sangat penting karena yang pertama dilihat oleh pengunjung dari sebuah restoran salah satunya adalah kebersihan. Jika restoran terlihat kotor dan tidak terawat, kepercayaan dan kenyamanan pengunjung akan restoran tersebut juga akan berkurang. Restoran yang bersih akan membuat pengunjungnya merasa nyaman dan mau untuk kembali lagi. Penilaian kebersihan ( cleanliness and hygiene) dapat dinilai dari:

a. Kebersihan fasilitas yang ada pada restoran

b. Kebersihan alat yang digunakan untuk memasak

c. Kebersihan dapur restoran (meskipun kurang tampak oleh tamu)

d. Kebersihan peralatan makan atau peralatan yang digunakan untuk menyajikan makanan

Kebersihan lingkungan restoran itu sendiri. ${ }^{6}$

\section{E. Simpulan}

Berdasarkan uraian di atas, dapat dapat disimpulkan:

Store Atmosphere dalam Bisnis Restoran atau Café meliputi Lay out di restoran kapal jodoh berfokus pada tempat duduk (kursi dan meja), Suara atau musik pada kapal jodoh merupakan hal penting untuk menjaga kenyamanan pengunjung sebagai sarana hiburan agar pengunjung tidak bosan dan jenuh. Suara deru ombak menjadi musik alami pada restoran kapal jodoh. Aroma laut menjadi pewangi alami agar menimbulkan kesan

\footnotetext{
${ }^{5}$ Yenny Logiawan dan Dr. Hartono Subagio,M.M., "Analisa Customer Value terhadap Customer Royalty dengan Customer Satisfaction sebagai Variabel Intervening pada Restoran Bandar Djakarta Surabaya”, Jurnal Manajemen Pemasaran Petra, Vol. 2, No. I (2014). 4.

${ }^{6}$ Priska V.M, Veranita G, Zeplin J.H.T dan Monika K., "Analisa Perbandingan Harapan dan Persepsi Pria dan Wanita dalam Memilih Sebuah Restoran di Surabaya Ditinjau dari Segi Meal Experience”, Jurnal Manajemen Perhotelan, Vol. 4, No. I (Maret 2008), 8.
}

60| Al-Iqtishod Volume. 8/ No. 2/Juli 2020 
menyatu dengan alam. Penggunaan kayu gelam dan pinus pada keseluruhan kapal, dikarenakan merujuk kepada sifat dan tekstur dari kedua kayu tersebut. Desain bangunan yang berupa kapal karam yang terdampar di pinggir pantai menjadi keunikan tersendiri yang dimiliki oleh restoran kapal jodoh. Area parkir yang luas, pencahayaan yang baik dan kualitas pelayanan yang baik merupakan temuan penelitian pada kapal jodoh.

Keputusan Pembelian dalam Bisnis Restoran atau Café dipengaruhi oleh Faktor keputusan pembelian berupa personal, psikologis, sosial dan kultural memberi dampak positif pada keputusan konsumen di kapal jodoh. Konsumen melakukan keputusan pembelian dikarenakan desain, suasana bangunan, tempat yang nyaman dan juga penghilang rasa penat. Harga makanan dan minuman, suasana hati pengunjung dan kebersihan merupakan temuan penelitian pada keputusan pembelian pada kapal jodoh.

\section{F. Daftar Pustaka}

Afifuddin. 2009. Metodologi Penelitian Kualitatif. Bandung: Pustaka Setia.

Atmaja, Desy Purwanti dan Martinus Febrian Adiwinata. 2013. Layanan Terhadap Keputusan Pembelian di Kopitiam Oey Surabaya. Vol I No 2. Jurnal Hospitality dan Manajemen Jasa.

Dessyana, Cindy Juwita. 2013. Store Atmosphere Pengaruhnya terhadap Keputusan Pembelian Konsumen di Texas Chicken Multimart II Manado. Volume I. Nomer 3. Jurnal $E M B A$.

Fahimah Achmad Fauzi DH Kadarisman Hidayat 2015. Pengaruh Store Atmosphere (Suasana Toko) terhadap Keputusan Pembelian (Survei pada Pengunjung di Madam Wang Secret Garden Café Malang). Volume 28 Nomer 2. November 2015. Jurnal Administrasi Bisnis.

Fahmi, Irham. 2016. Perilaku Konsumen. Bandung: Alfabeta.

Gunawan, Imam. 20I3. Metode Penelitian Kualitatif. Jakarta:PT bumi aksara.

https://www.kompas.tv/article/29838/kapal-jodoh-tempat-makan-berbentuk-kapalkaram

Lily Harlina Putri, Dkk. 20I4. Pengaruh Store Atmosphere terhadap Keputusan Pembelian dan Kepuasan Pelanggan (Studi Pada Monopoli Café and Resto Soekarno Hatta Malang). Volume I5 Nomer 2. Oktober 20I4. Jurnal Administrasi Bisnis. 
Store Atmosphere ...

Logiawan, Yenny dan Dr. Hartono Subagio,M.M. 20I4. Analisa Customer Value terhadap Customer Royalty dengan Customer Satisfaction sebagai Variabel Intervening pada Restoran Bandar Djakarta Surabaya. Vol. 2, No. I. Jurnal Manajemen Pemasaran Petra.

Meleong, Lexi J. 20I0. Metodologi Penelitian Kualitatif. Bandung: PT. Rosdakarya.

Millisani Yusuf 2018. Keputusan Pembelian yang dipengaruhi Store Atmosphere pada pusat Handphone dan Aksesoris Radja Cellular Bangkalan. Madura : Universitas Trunojoyo Madura. Jurnal Ebis Fakultas Ekonomi dan Bisnis

Mowen, Jhon C. dan Michael Minor. 2002. Perilaku Konsumen. Jilid Kedua. Alih Bahasa: Dwi Kartini. Jakarta: Erlangga.

Normasari, Selvy dkk. 2013. Pengaruh Kualitas Pelayanan Terhadap Kepuasan Pelanggan, Citra Perusahaan Dan Loyalitas Pelanggan (Survei pada Tamu Pelanggan yang Menginap di Hotel Pelangi Malang). Vol 6, No 2. Jurnal Administrasi Bisnis (JAB).

Noviawaty dan Beli Yuliandi. 20I4. Pengaruh Store Atmosphere Terhadap Keputusan Pembelian Konsumen Pada Outlet Nyenyes Palembang. Volume I2, Nomer I.

Priska V.M dkk. 2008. Analisa Perbandingan Harapan dan Persepsi Pria dan Wanita dalam Memilih Sebuah Restoran di Surabaya Ditinjau dari Segi Meal Experience. Vol. 4 No. I. Jurnal Manajemen Perhotelan.

Putri, Lily Harlina Dkk. 20I4. Pengaruh Store Atmosphere Terhadap Keputusan Pembelian Dan Kepuasan Pelanggan (Studi Pada Monopoli Café and Resto Soekarno Hatta Malang). Volume I5 Nomer 2. Jurnal Administrasi Bisnis.

Putri, Lily Harlina Dkk. 20I4. Pengaruh Store Atmosphere Terhadap Keputusan Pembelian Dan Kepuasan Pelanggan (Studi Pada Monopoli Café and Resto Soekarno Hatta Malang). Volume I5 Nomer 2. Jurnal Administrasi Bisnis.

Santon, William J 1994. Prinsip-prinsip Pemasaran. Jakarta: Erlangga.

Savitri, Mila Andria. Peran Pencahayaan Buatan salam Pembentukan Suasana dan Citra Ruang Komersial. Studi Kasus pada Interior Beberapa Restoran Tematik di Bandung. Jurnal Ambience.

Sugiyono. 2012. Metode Penelitian Kuantitatif Kualitatif dan R\&D. Bandung: CV Alfabeta.

Sumarwan, Ujang. 20I I. Perilaku Konsumen Edisi Kedua. Bogor: Ghalia Indonesia.

Sustina 200I. Perilaku Konsumen dan Komunikasi Pemasaran. PT. Remaja Rosdakarya. Bandung.

Tjiptono, dkk. 2016. Pemasaran. Yogyakarta: Andi.

Usmara, Usi 2008. Pemikiran Kreatif Pemasaran. Yogyakarta: Amara Books. 